\title{
Plant Noncoding RNAs Identification and Characterization - A
}

\section{Short Review}

\author{
Paul P1* and Dhandapani $\mathrm{V}^{2}$ \\ ${ }^{1}$ School of Life Sciences, University of Warwick, Coventry, United Kingdom \\ ${ }^{2}$ School of Biosciences, University of Birmingham, Birmingham, United Kingdom \\ *Corresponding author: Parameswari Paul, School of Life Sciences, University of \\ Warwick, Coventry, United Kingdom, Email: parameswaripaul@gmail.com
}

\section{Mini Review \\ Volume 2 Issue 1}

Received Date: June 15, 2019

Published Date: June 26, 2019

DOI: $10.23880 /$ aabsc-16000134

\begin{abstract}
Advances in sequencing technologies have facilitated multitudinal research analysis. Ample number of genes, transcriptional factors, gene families and genes associated to agronomical traits has been discovered. Similarly, several noncoding RNA (ncRNA) transcripts have also been identified which are researchers interest these days. RNA molecules that are not translated to a protein molecule are marked as ncRNA. They are categorized based on their size to small and long non-coding RNAs (IncRNA). Several ncRNAs have been identified in plants and animals, however many among them are yet to be characterized or proven with any biological roles. In this review we discuss the advancement of ncRNA research in plants and focus in their identification, types and characterization with the available resources.

Keywords: Noncoding; Small Noncoding RNAs; Traits; Long Non-Coding RNAs
\end{abstract}

\section{Introduction}

RNA molecule that is not translated into a protein molecule is termed as ncRNAs. They are known to regulate genes while playing major roles in plant growth and stress tolerance [1,2]. NcRNAs are categorized into two groups based on their size into small and long noncoding RNAs; where microRNAs (miRNA), small interfering RNAs (siRNAs), form the first group with $<50$ nucleotide (nt) length and long noncoding RNAs like long intergenic RNAs (lincRNAs), circular RNAs (circRNAs) forming the second group of regulatory ncRNAs with a length $>200 \mathrm{nt}$ [3]. Among the different classes of ncRNAs miRNAs and lncRNAs are researchers interest these days. MiRNAs are the widely known small ncRNA with 18-24 nucleotides (nt) length abundantly found in plants and animals. They are transcribed as pri-miRNAs in the nucleus by RNA polymerase II, processed by Dicer-like 1 into pre-miRNAs forming a hairpin structure. Later they are loaded into the Argonaute (AGO) protein complex to execute their functions [3]. MiRNAs regulate gene expression by complementary binding to specific mRNAs and function through post transcriptional gene silencing $[3,4]$. Subsequently, IncRNAs are potential biological regulators that have originated as the reason of transposable element insertions, chromosomal rearrangement or as a cause of mutations in coding genes [5]. A large number of ncRNAs have been identified and characterized in plants such as Arabidopsis thaliana (A. thaliana), Zea mays (Z. mays) and Medicago truncatura (M. trunculata) [5-7]. The availability of sequence information as expressed sequence tags (ESTs), complementary DNA (cDNA), microarray, whole genome sequence (WGS), and RNA sequencing (RNA seq) have enabled the identification of both the ncRNAs. Besides these, the advancement in sequencing technologies has provided a paradigm in ncRNA research. 


\section{Identification and Characterization of ncRNAs in Plants}

Cloning the small RNA and comparative were the initial methods followed in identification of miRNAs. In 2002 Reinhart BJ, et al., used these techniques to identify 16 Arabidopsis thaliana (A. thaliana) miRNAs showing different expression pattern during different developmental stages. This method was overcome by their identification of miRNAs from ESTs in plants like $A$. thaliana, O. sativa, B. rapa [8-10]. The advent of NGS technologies like small RNA sequencing has been the widely used method recently for the identification of miRNAs. These methods have enabled several genome wide identifications which enriched our knowledge with growing number ncRNAs publicly available. Also, bioinformatics methods have enabled the target prediction for these miRNAs. The identified miRNAs are evidenced to involved in many developmental process, biotic and abiotic stress responses [11,12]. Several miRNAs have been proven to involve in floral development, leaf formation, stem development, root development, signal transduction, male and female reproductive development, and many other cellular processes in several plants [13-21].

Similarly, a large number of lncRNA have been identified and characterized in plants utilizing cDNA sequences, RNA sequencing and strand specific RNA sequencing technologies [6,22-24]. Besides their regulatory roles few IncRNAs are known to play roles in phosphate-starvation, nodulation and cold stress [25]. Although several lncRNAs have been identified, most of their functions yet remain unknown. A very small number of plant lncRNAs have been characterized thus far. The most well-known IncRNAs COOLAIR and COLDAIR identified in Arabidopsis relate to the flowering locus (FLC) and function during flowering time [26,27]. LncRNAs, GmRNAD40 and MtENOD40 identified in soybean and Arabidopsis mediate nodule formation [28,29]. Other IncRNAs functioning in phosphate uptake have also been reported in tomato, rice and barley $[25,30,31]$. In plants like maize more than $90 \%$ of IncRNAs are known to function as precursors of small RNAs [7].

\section{Experimental Validation}

Besides genome wide identification, validation of these miRNAs and IncRNAs using experimental procedures are also in the increasing phase. MiRNAs are generally validated using RT-QPCR (real time methods), however for few miRNAs their stem loop structure makes it difficult in their identification. Hence several arraybased methods and northern blot techniques have become the major techniques used in the miRNA validation [32]. The next step after the miRNA validation is the target validation which helps major to understand the impact of the miRNA on the gene of interest. Rapid Amplification of cDNA ends (RACE) techniques and RLMRACE are the widely used techniques for the target validation on small scale [33]. Degradome sequencing is an emerging technique for the miRNA-target validation on genome wide basis, however RLM-RACE (RNA Ligase Mediated RACE) is the most widely accepted validation method for the miRNA mediated cleavage. Similarly, IncRNA are generally validated using RT-PCR methods.

\section{Recent Trend in ncRNA Identification}

NcRNA identification keeps evolving with the advancing technologies. Recently miRNA sequencing (miRNA seq) and lncRNA sequencing (lncRNA seq) are the techniques designed to focus on the ncRNAs of interest only. Such studies have identified several new miRNAs and IncRNAs that have not been identified earlier [34]. However, these methods seem highly expensive techniques, RNA seq experiments have been the most widely used and cost-effective method in the identification of these ncRNAs.

\section{References}

1. Kapranov P, Cheng J, Dike S, Nix DA, Duttagupta R, et al. (2007) RNA maps reveal new RNA classes and a possible function for pervasive transcription. Science 316(5830): 1484-1488.

2. Bartel DP (2004) MicroRNAs: genomics, biogenesis, mechanism, and function. Cell 116(2): 281-297.

3. St Laurent G, Wahlestedt C, Kapranov P (2015) The Landscape of long noncoding RNA classification. Trends in genetics 31(5): 239-251.

4. Voinnet $O$ (2009) Origin, biogenesis, and activity of plant microRNAs. Cell 136(4): 669-687.

5. Kapusta A, Kronenberg Z, Lynch VJ, Zhuo X, Ramsay L, et al. (2013) Transposable Elements Are Major Contributors to the Origin, Diversification, and Regulation of Vertebrate Long Noncoding RNAs. PLoS Genetics 9(4): e1003470.

6. Liu J, Jung $\mathrm{C}, \mathrm{Xu} \mathrm{J}$, Wang $\mathrm{H}$, Deng S, et al. (2012) Genome-wide analysis uncovers regulation of long 
intergenic noncoding RNAs in Arabidopsis. Plant Cell 24(11): 4333-4345.

7. Li L, Eichten SR, Shimizu R, Petsch K, Yeh CT, et al. (2014) Genome-wide discovery and characterization of maize long non-coding RNAs. Genome Biol 15(2): R40.

8. Zhang L, Chia JM, Kumari S, Stein JC, Liu Z, et al. (2009) Genome-wide characterization of microRNA genes in maize. PLoS Genet 5(11): e1000716.

9. Dhandapani V, Ramchiary N, Paul P, Kim J, Choi SH, et al. (2011) Identification of potential microRNAs and their targets in Brassica rapa L. Mol Cells 32(1): 2137.

10. Archak S, Nagaraju J (2007) Computational prediction of rice (Oryza sativa) miRNA targets. Genomics Proteomics Bioinformatics 5(3-4): 196-206.

11. Chen X (2009) Small RNAs and their roles in plant development. Annu Rev Cell Dev Biol 25: 21-44.

12. Enhui Shen, Jun Zou, Falk Hubertus Behrens, Li Chen, Chuyu Ye, et al. (2015) Identification, evolution, and expression partitioning of miRNAs in allopolyploid Brassica napus. J Exp Bot 66(22): 7241-7253.

13. Chen X (2004) A microRNA as a translational repressor of APETALA2 in Arabidopsis flower development. Science 303: 2022-2025.

14. Nag A, Jack T (2010) Sculpting the flower; the role of microRNAs in flower development. Current topics in developmental biology 91: 349-378.

15. Palatnik JF, Allen E, Wu X, Schommer C, Schwab R, et al. (2003) Control of leaf morphogenesis by microRNAs. Nature 425(6955): 257-263.

16. Mallory AC, Dugas DV, Bartel DP, Bartel B (2004) MicroRNA regulation of NAC domain targets is required for proper formation and separation of adjacent embryonic, vegetative, and floral organs. Curr Biol 14(12): 1035-1046.

17. Guo HS, Xie Q, Fei JF, Chua NH (2005) MicroRNA directs mRNA cleavage of the transcription factor NAC1 to downregulate auxin signals for Arabidopsis lateral root development. Plant Cell 17(5): 13761386.

18. Wu G, Poethig RS (2006) Temporal regulation of shoot development in Arabidopsis thaliana by
miR156 and its target SPL3. Development 133(18): 3539-3547.

19. Ambros V, Chen XM (2007) The regulation of genes and genomes by small RNAs. Development 134(9): 1635-1641.

20. Carrington JC, Ambros V (2003) Role of microRNAs in plant and animal development. Science 301(5631): 336-338.

21. Zhang BH, Pan XP, Cobb GP, Anderson TA (2007) microRNAs as oncogenes and tumor suppressors. Developmental Biology 302(1): 1-12.

22. Li L, Eichten SR, Shimizu R, Petsch K, Yeh CT, et al. (2014) Genome-wide discovery and characterization of maize long non-coding RNAs. Genome Biol 15(2): R40.

23. Wen J, Parker BJ, Weiller GF (2007) In silico identification and characterization of mRNA-like noncoding transcripts in Medicago truncatula. In Silico Biol 7(4-5): 485-505.

24. Parameswari P, Vignesh D, Su RC, Yong PL (2016) Genome wide identification and functional prediction of long non-coding RNAs in Brassica rapa. Genes \& Genomics Page 38(6): 547-555.

25. Liu C, Muchhal US, Raghothama KG (1997) Differential expression of TPS11, a phosphate starvation-induced gene in tomato. Plant Mol Biol 33(5): 867-874.

26. Swiezewski S, Liu F, Magsin A, Dean C (2009) Coldinduced silencing by long antisense transcripts of an Arabidopsis Polycomb target. Nature 462(7274): 799-802.

27. Heo JB, Sung S (2011) Vernalization-mediated epigenetic silencing by a long intronic non coding RNA. Science 331(6013): 76-79.

28. Yang WC, Katinakis $P$, Hendriks P, Smolders A, de Vries F, et al. (1993) Characterization of GmENOD40, a gene showing novel patterns of cell specific expression during soybean nodule development. The Plant Journal 3(4): 573-585.

29. Crespi MD, Jurkevitch E, Poiret M, d'Aubenton-Carafa Y, Petrovics G, et al. (1994) Enod40, a Gene Expressed During Nodule Organogenesis, Codes for a Non- 
Translatable RNA Involved in Plant Growth. The Embo J 13(21): 5099-5112.

30. Kouchi H, Takane K, So RB, Ladha JK, Reddy PM (1999) Rice ENOD40: isolation and expression analysis in rice and transgenic soybean root nodules. Plant J 18(2): 121-129.

31. Huang CY, Shirley N, Genc Y, Shi B, Langridge P (2011) Phosphate utilization efficiency correlated with expression of low-affinity phosphate transporters and noncoding RNA, IPSI, in barley. Plant Physiol 156(3): 1217-1229.
32. Chen C, Tan R, Wong L, Fekete R, Halsey J (2011) Quantitation of microRNAs by real-time RT-qPCR. Methods Mol Biol 687: 113-134.

33. Yeku O, Frohman MA (2011) Rapid amplification of cDNA ends (RACE). Methods Mol Biol 703: 107-122.

34. Chen L, Shi S, Jiang N, Khanzada H, Wassan GM, et al. (2018) Genome-wide analysis of long non-coding RNAs affecting roots development at an early stage in the rice response to cadmium stress. BMC Genomics 19(1): 460. 